\title{
"I failed because I was Playing Videogames": An Examination of Undergraduate Males Videogame Addiction and Academic Performance
}

\author{
${ }^{1}$ Onyemaka, S. B., ${ }^{1}$ Igbokwe, D. O. PhD, ${ }^{1}$ Adekeye, O. A. \\ $\&^{2}$ Agbu, Jane-Frances Ph.D \\ ${ }^{\mathbf{1}}$ Psychology Department, \\ College of Leadership Development Studies, \\ Covenant University, Ota, Ogun State, Nigeria. \\ david.igbokwe@covenantuniversity.edu.ng, \\ ${ }^{2}$ School of Health Sciences \\ National Open University of Nigeria \\ Victoria Island, Lagos, Lagos State. \\ agbujane2005@yahoo.com.
}

\begin{abstract}
Many factors affect the academic performance of undergraduate students. Playing videogames among male student's vis-àvis their academic performance was assessed in this study. This study employed two hundred and fifty male undergraduate students (250) aged between 15 and $23(M=17.44, S D=1.37)$, selected from a Nigerian private University. Academic performance was assessed using Cumulative Grade Point Average (CGPA) collapsed into three groups (viz: $1=1.25$ to $3.49,2=3.50$ to 4.49 and $3=4.50$ to 5.00 ). Pathological playing of videogames was assessed using the Problem Video Game Playing questionnaire (PVP). A statistical significant difference at the $\mathrm{p}<$ .05 level was observed $F(2,250)=5.15, p=.01$. The small effect size of 0.04 was obtained using the partial eta squared. A Post-hoc comparison using Tukey HSD test indicated that group 1 differed significantly in their mean scores from group 2 and 3. Further analysis with Pearson Product Moment Correlation Coefficient showed $r=-.262, n=250, \mathrm{p}<.000$ and $r$ $=.261, n=250, \mathrm{p}<.000$ for CGPA and self-reported grades respectively. It was concluded that videogame addiction has a significant effect on the academic performance of male undergraduate students.
\end{abstract}




\section{Introduction}

Pathological video gaming has been found to be prevalent among adolescents with some of its attendant negative effects ranging from: "lower social competence" to "lower school performance" (Gentile, Choo, Liau, Sim, Li, Fung \& Khoo, 2011, e319). Some of the reasons why young people are motivated to play games include for: "(i) entertainment (ii) escapism, and/or (iii) virtual friendship" (Beranuy, Carbonell \& Griffiths, 2013, p. 149). When these basic motivations for playing video games become relatively met and the young person still indulges in playing video games, then, addiction is probably the next stage that they enter into with its consequent "psychological dependence and serious life conflicts" (Beranuy, et al., 2013, p. 149).

The challenge with videogame addiction is that, "videogame playing ... shares many similarities with gambling" (Griffiths \& Wood, 2000, p.199). In fact, Fisher (1994) had earlier reported that video game playing may lead to a behavioural pattern akin to gambling addiction. Salguero and Moran (2002) believe that problems arising with excessive video game use tend to look like dependence syndromes. Interestingly, the similarity between video game addiction and other addictive behaviour has been reported to be stronger that had been previously thought (Gentile et al, 2011) with addicts manifesting similar results of effects of video game addiction as in other substance addictions (Beranuy et $a l ., 2013)$. This finding underscores the need to investigate the presence of videogame addiction in Nigeria in order to examine its prevalence.

Generally, males tend to be more drawn to video game playing than females (Faulkner, Irving, Adlaf \& Turner, 2014). Male gender has been found to be principally positively associated with video game addiction (Wittek et al., 2015). Lucas and Sherry (2004) sampled 544 college students comprising of $57.5 \%$ females (313) and $42.5 \%$ males (231) and their results showed that more males (88.3\%) played games every week than females $(54.6 \%)$ despite the fact that $15 \%$ more females were sampled. Authors tend to also observe a preponderance of males as players of video game than females in their samples even after eliminating non players. For instance, Puri and Pugliese (2012) after eliminating non players from their samples, examined the 175 responses they sampled and found that, "133 $(76 \%)$ were males and 42 (24\%) were females" (P. 349).

The preponderance of males in videogame addiction was highlighted further in a study by Lucas and Sherry (2004) who reported that women have been found to play videogames less than males by averaging 4.2 hours weekly play while males averaged 11 hours weekly play. The male majority in video game addiction has also been reported by Ko, Yen, Chen, Chen and Yen (2005) in their study of Taiwaneese adolescents. Even when researchers selected more females than males in a multiple sample study, with females being more than males, the result showed a gender difference in favour of males in videogame playing. This was reflected by Greenberg, Sherry, Lachlan, Lucas and Holmstrom (2010) who found that 
males $(\mathrm{n}=551)$ generally played games about twice more than females $(\mathrm{n}=$ $685)$ at $5^{\text {th }}$ grade, $8^{\text {th }}$ grade, $11^{\text {th }}$ grade and college levels with each gender playing for 18.56 hours and 8.16 hours weekly for males and females respectively.

In contrast to the plethora of studies supporting a negative effect of video game on the academic performance of adolescents, Drummond and Sauer (2014, p.3) found "no evidence that academic performance in science, mathematics or reading ability, declined as a function of increased gameplay frequency, for single player or multiplayer videogame use." Their study is distinctively interesting because they used a large sample size of 192, 975 students from 22 countries in their study. However, for future research, Drummond and Sauer (2014) suggested that "focusing upon any one school is unlikely to provide a good understanding of video-gaming effects on academic achievement" (p.4). This suggestion seems vertically thought out instead of laterally focused because it tends to put an end to the debate on this interesting topic irrespective of the clime. This is because Nigeria and even the whole continent of Africa is not a part of the countries within the Organization for Economic Cooperation and Development (OECD) countries sampled for Drummond and Sauer's (2014) study. This further highlights the need for the present study in Nigeria.

Some researchers have used only males to conduct empirical studies on video game playing. An example of this is the study on "The role of violent video game content in adolescent development: Boys' perspectives" (Olson, Kutner, \& Warner, 2008). As a result of more males playing video games than females, Schmitt and Livingston (2015) focused their study on 477 male college students. One of the principal reasons a preponderance of males are used in videogame addiction studies was highlighted by Mentzoni et al., (2011) when they found that being a young male is the strongest predictor of problem video game use. Mentzoni et al., (2011) reported that in comparison with females, males tend to manifest more problematic videogame use than females. They reported the highest age of problem use to be $16-21$ years. The disinterest of Nigerian females in videogame playing has been noted in the procedure section of the present study. This seems not to be particularly peculiar to Nigeria alone. For instance, Mentzone et al., (2011) reported that $65 \%$ of the males they sampled for their study reported regular video games use while $56.6 \%$ of females reported not using video games.

In order to examine the effect of videogame addiction on academic performance of male undergraduates, the authors hypothesized that there will be an effect of videogame addiction on the academic performance of male university undergraduates. The authors also hypothesized that there will be a relationship between male undergraduates playing of videogame and their self-reported and actual (school calculated) academic performance. 


\section{Methods}

A correlational research design was applied to examine the relationship between the two variables from a cross section of male university undergraduates using a self-report measure. Two hundred and fifty (250) male students aged between 15 and 23 ( $M=17.44, S D=1.37)$, were selected from two colleges of Covenant University (College of Development Studies and College of Science and Technology) for this study. The initial research protocol factored in females as part of the samples but during the course of the research all the female students approached as respondents declined to participate pointing out that they do not play video games hence, will not respond to the questionnaire items. When they were asked by the researchers what they do which take their time, they responded: "watching Korean and South American Soap Operas." Since this was not part of the research focus, they were excluded. However, this might be a good research area in the future. The participants for this study were approached in the College buildings of CDS and CST and the questionnaires were administered to them in their classes with the females opting out of participation. The questionnaires took about ten to fifteen minutes to complete.

\section{Instrument}

A questionnaire with two sections viz: demographic variables (which also captures their Cumulative Grade Point Average (CGPA) and their selfreported grades) and the Problem Video Game Playing (PVP) were administered. The PVP questionnaire is one of the most widely used measures in assessing videogame addiction among young people (Beranuy et al, 2013). The PVP was developed in 2002 by Salguero and Moran using 223 Spanish adolescents. It is a 9-item questionnaire with a dichotomous response option. The PVP has a Cronbach alpha of 0.69. There is a positive correction between PVP and the severity of dependence scale. There is also a positive correlation between PVP scores and duration of videogame play among adolescents. A Cronbach alpha of .70 and a Spearman Brown split half reliability of .72 for equal length and .72 for unequal length were established for the PVP in this study. 


\section{Results}

Table 1: One-Way ANOVA and Descriptive Statistics on the influence of videogame addiction on academic performance

\begin{tabular}{lccccccc}
\hline Cumulative GPA & \multicolumn{2}{c}{ Video Game Addiction } & \multicolumn{3}{c}{ 95\% CI for Mean } & \\
\hline & Group & Mean & SD & n & Difference \\
\hline Group 1 & 1.25 to 3.49 CGPA & 3.64 & 2.22 & 67 & $3.10,4.18$ & \\
Group 2 & 3.50 to 4.49 CGPA & 2.80 & 2.09 & 149 & $2.46,3.14$ & \\
Group 3 & 4.50 to 5.00 CGPA & 2.44 & 1.62 & 34 & $1.88,3.01$ & \\
\hline Source & \multirow{2}{*}{ Sum of Square } & df & MS & F & Sig. & eta \\
\hline Between Groups & 44.11 & 2 & 22.06 & 5.15 & $.01 *$ & 04 \\
Within Groups & 1057.75 & 247 & 4.28 & & & \\
Total & 1101.86 & 249 & & & & \\
\hline
\end{tabular}

$* \mathbf{p}<.05$.

Table 2: Multiple comparisons of mean difference of participants on the influence of videogame addiction on academic performance

Multiple Comparisons

\begin{tabular}{lcc}
\hline Group (I) & Group (J) & Mean Difference (I - J) \\
\hline$<=3.49$ & $3.50-4.49$ & $.84^{*}$ \\
& $4.50+$ & $1.20^{*}$ \\
$3.50-4.49$ & $<=3.49$ & $-.84^{*}$ \\
$4.50+$ & $4.50+$ & $N S$ \\
& $<=3.49$ & $-1.20^{*}$ \\
\hline$* \mathrm{p}<.05 . ; N S=$ Not Significant & $N S$
\end{tabular}

Table 1 shows the result of a one-way analysis of variance conducted to test the influence of videogame addiction on academic performance of participants. The result showed a statistically significant difference in the academic performance scores of the three groups at the $p<.05$ level of significance: $F(2,247)=5.15, p=$ 0.01 . The effect size was calculated using eta squared and a small effect size of 0.04 was obtained. A Post-hoc comparison using the Tukey HSD test (Table 2) indicated that the mean score 
for group $1(M=3.64, S D=2.22)$ was significantly different from Group 2 $(M=2.80, S D=2.09)$ and Group $3(M$ $=2.44, S D=1.62)$. Group 1 showed the highest significance from Group 2, and 3. From the result there is a significant influence of videogame addiction on the academic performance of male undergraduate students in the selected Nigerian private University. The result also showed that the higher the video game addiction, the lower the male students CGPA and vice versa (figure 1).

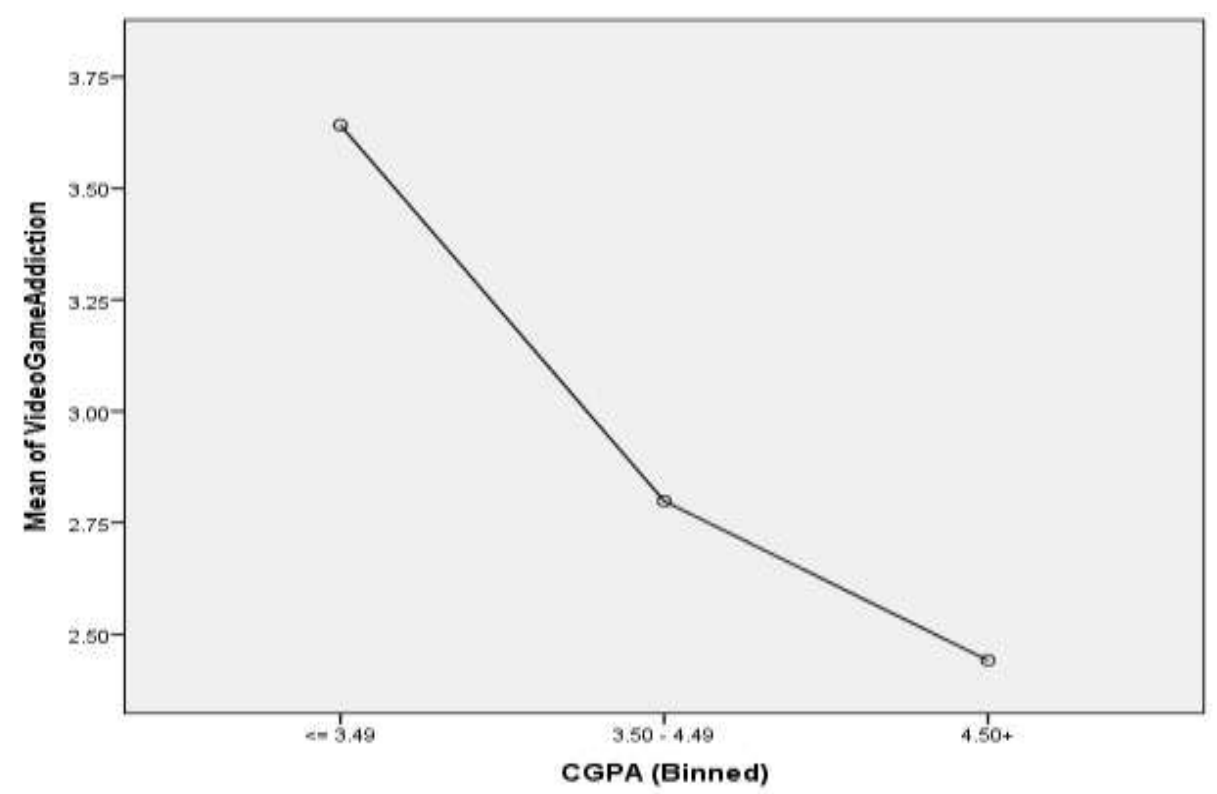

Figure 1: The mean scores of videogame addiction on academic performance (CGPA in 3 categories)

Table 3: Result of Pearson Product Moment Correlation Coefficient (PPMCC) on the relationship between videogame addiction and academic performance measured with CGPA

\begin{tabular}{|c|c|c|c|c|c|c|c|c|}
\hline \multicolumn{9}{|c|}{ Videogame Addiction \& CGPA } \\
\hline \multirow[b]{2}{*}{ Variable } & \multicolumn{3}{|c|}{ Video Game Addiction } & \multirow[b]{2}{*}{$\mathrm{n}$} & \multicolumn{2}{|c|}{ CGPA } & \multirow[b]{2}{*}{$\mathrm{n}$} & \multirow[b]{2}{*}{$\mathrm{r}$} \\
\hline & & $\mathrm{M}$ & SD & & M & SD & & \\
\hline Videogame & Addiction \& CGPA & 3.81 & .61 & 250 & 2.98 & 2.10 & 250 & $-.262 * *$ \\
\hline
\end{tabular}

Table 3 shows the result of a PPMCC conducted on the relationship between videogame addiction and Academic performance measured with CGPA. 
The result showed a significantly negative relationship between videogame addiction and academic performance measured with the CGPA $(r=-.262)$ of male undergraduate students. From the result of the
PPMCC, it is evident that as videogame addiction increases, the academic performance measured objectively with male student's CGPA decreases.

Table 4: Result of Pearson Product Moment Correlation Coefficient (PPMCC) on the relationship between videogame addiction and self-reported academic performance

Videogame Addiction \& Self-Reported Grades

Video Game Addiction $\quad$ Self-reported Grades

\begin{tabular}{lccccccc} 
Variable & $\mathrm{M}$ & $\mathrm{SD}$ & $\mathrm{n}$ & $\mathrm{M}$ & $\mathrm{SD}$ & $\mathrm{n}$ & $\mathrm{r}$ \\
\hline Videogame Addiction \& Grades & 2.98 & 2.10 & 250 & 2.78 & 1.22 & 250 & $.261^{* *}$
\end{tabular}

$\overline{\mathrm{p}<.01^{*}}$

Table 4 shows the result of a PPMCC conducted on the relationship between videogame addiction and self-reported academic performance. The result paradoxically showed a significant relationship between videogame addiction and self-reported academic performance $(r=.261)$. From the result of the PPMCC, it is evident that as videogame addiction increases, the self-reported academic performance measured through subjective personal assessment of participants by themselves increases.

\section{Discussion}

Our findings in this study shows that video game addiction adversely affects academic performance when academic performance is objectively measured using male undergraduate students CGPA but when academic performance is subjectively measured using students self-reported grades, there is no negative effect of videogame addiction on academic performance.

A negative relationship between videogame addiction and academic performance was found by Schmitt and Livingston (2015). They reported a negative correlation between videogame addiction and college GPA in their one year longitudinal study of males in Minnesota, USA. An adverse effect of videogame addiction was also found by Chiu, Lee and Huang (2004) who reported a negative association between videogame addiction and academic achievement among Taiwanese adolescents. Our study also agrees with the findings of Anand (2007) who reported a negative correlation between the time students invest into playing videogame and their academic performance. In concurrence with our study, Weis and Cerankosky (2010) also found a negative impact of videogame addiction on academic performance. 
Weis and Cerankosky (2010, p.463) in an attempt to present a reason why videogame addiction has an adverse effect on academic performance noted that, "...video games may displace after-school activities that have educational value and may interfere with the development of reading and writing skills in some children." They sample 6 to 9 year old young boys for their study and their findings imply that videogame addiction and its attendant negative effect on academic performance extends to children too.

The detrimental effect of videogame addiction on academic performance was specifically measured by Anand (2007) with objective measures using GPA and SAT scores and noted that both scores decreased as videogame usage increased. The use of objective measure such as the GPA in our study and that of Anand (2007, p.552) and the resulting negative correlation with academic performance shows that, for students to maintain good grades, a reduction in videogame use is nonnegotiable. One of the reason which has been adduced for this negative effect of videogame on academic performance is that the more students spend time playing videogames, the more they have less time for academic work which inevitably translates to lower performance (Haghbin, Shaterian, Hosseinzadeh \& Griffith, 2013).

In line with our finding, Gentile (2009) found that pathological gamers spent more time playing, had lower grades and attention issue than did their non-pathological counterparts. The negative academic performance could be as a result of negative investment of their time. For instance, Wood, Griffiths and Parke (2007) found that young people tend to lose the time they are supposed to use doing other things while playing video games. The pervasive nature of videogame addiction among adolescents (Grusser, Thalemann \& Griffiths, 2007) has been found not only to negatively affect academic performance (Barlett et al., 2009; Schmitt \& Livingston, 2015) but has also been found to affect overall college engagement by male college students (Schmitt \& Livingston, 2015).

Videogame addiction not only correlates negatively with academic performance, but Rehbein, Kleimann and Moble (2010, p. 269) reported that video game dependency "is accompanied by increased levels of psychological and social stress in the form of lower school achievement, increased truancy, reduced sleep time, limited leisure activities, and increased thoughts of committing suicide." Chiu, Lee and Huang (2004) added that videogame addiction is related to hostile behavior among young people while Quaresh, Khan and Masroor (2013) in addition to increased aggression added that videogame addiction can induce feelings of loneliness among adolescents. The plethora of other effects of videogame addiction underscores the need for clinicians to tenaciously intervene.

Although there is mounting evidence in scientific literature on the negative effect of videogame addiction on academic performance (Anand, 2007; Bartlett et al, 2009; Gentile, 2009; Schmitt \& Livingston, 2015) as shown in this study, some authors are 
however of the opinion that, "the impact of video-gaming on academic performance is too small to be considered problematic" (Drummond \& Sauer, 2014). Surprisingly, this is also empirically supported. However, since studies that are in support of videogame addiction having a negative effect on academic performance including ours almost drowns out studies that are not in concurrence with the effect of videogame addiction on academic performance, it is our position that there is a negative effect of videogame addiction on academic performance from the outcome of our study. The positive correlation from our participant's subjective selfreported grade should be taken as outcome of a self-reported grade, taking into cognizance, social desirability and how people tend to strive to appear socially desirable.

\section{References}

Anand, V. (2007). Study of Time Management: The Correlation between Video Game Usage and Academic Performance Markers. CyberPsychology \& Behavior, 10(4): 552-559.

Barlett, C. P., Anderson, C. A., Swing, E. L. (2009) Video game effects - Confirmed, suspected, and speculative. A review of the evidence. Simulation and Gaming 40: 377-403. doi: 10.1177/1046878108327539

Beranuy, M., Carbonell, X. \& Griffiths, M. D. (2013). A Qualitative analysis of online gaming addicts in treatment. International journal of mental health addiction, 11: $149-161$.
The result of our study should be generalized with caution. In fact it can only be used vis-à-vis the male gender as only males were selected for this study as reported in the methods section. Apart from that, the fact that it was conducted in a private university is also another point of caution. Future studies should include females and also include different university settings like federal and state universities (public universities). Apart from the aforementioned caveat in generalization, this study has contributed positively to the growing body of knowledge on the effect of videogame addiction on academic performance and has added an interesting point, the fact that student's self-reported grades might not effectively capture their academic performance.

Chiu, S. I., Lee, J. Z. \& Huang, D. H. (2004). Video Game Addiction in Children and Teenagers in Taiwan. CyberPsychology \& Behavior, 7(5): 571-581.

Drummond A \& Sauer, J. D. (2014). Video-games do not negatively impact adolescent academic performance in science, mathematics or reading. PLoS ONE 9(4): e87943. doi:10.1371/journal.pone.008794 3. Retrieved from: http://www.ncbi.nlm.nih.gov/pmc /articles/PMC3974676/pdf/pone. 0087943.pdf

Faulkner, G., Irving, H., Adlaf, E. M. \& Turner, N. (2014). Subtypes of adolescent video gamers: A latent class analysis. International 
journal of mental health addiction, Retrieved from: http://link.springer.com/article/10 .1007/s11469-014-9501-6

Fisher, S. (1994). Identifying video game addiction in children and adolescents. Addictive behaviours, 19 (5): 545 - 553.

Gentile, D. (2009). Pathological Video-Game Use among Youth Ages 8 to 18: A National Study. Psychological Science, 20 (5):594 - 602.

Gentile, D. A., Choo, H., Liau, A., Sim, T., Li, D., Fung, D. \& Khoo, A. (2011). Pathological video game use among youths: A TwoYear Longitudinal Study. Pediatrics, 127 (2):e319 - e329. Retrieved from: https://www.sfu.ca/cmns/courses/ 2011/325/class/13zachary/3_final _project/Misc_files/Pathological \%20Game\%20Use.pdf

Greenberg, B. S., Sherry, J., Lachlan, K., Lucas, $\mathrm{k} \&$ Holmstrom, A. (2010). Orientation to video game among gender and age groups. Simulation and gaming, 41 (2): $238-259$.

Griffiths, M. \& Wood, R. T. A. (2000). Risk Factors in Adolescence: The Case of Gambling, Videogame Playing, and the Internet. Journal of gambling studies, 16 (2): 199 225.

Grusser, S. M., Thalemann, R. \& Griffiths, M. D. (2007). Excessive Computer Game Playing: Evidence for Addiction and Aggression? CyberPsychology \& Behavior, 10 (2): 290-292.
Haghbin, M., Shaterian, F., Hosseinzadeh, D. \& Griffith, M. D. (2013). A brief report on the relationship between self-control, video game addiction and academic achievement in normal and ADHD student. Journal of Behavioral Addictions, 2(4):239243.

Ko, C. H., Yen, J. Y., Chen, C. C., Chen, S. H. \& Yen, C. F. (2005). Gender Differences and Related Factors Affecting Online Gaming Addiction Among Taiwanese Adolescents. The Journal of Nervous and Mental Disease, 193 (4): $273-277$

Lucas, K. \& Sherry, J. L. (2004). Sex Differences in Video Game Play: A Communication-Based Explanation. Communication research, 31 (5): 499 - 523. Retrieved from: http://crx.sagepub.com/content/3 $1 / 5 / 499$

Mentzoni, R. A., Brunborg, G. S., Molde, h., Myrseth, H., Skouveroe, K. J. M., Hetland, J. \& Pallesen, S. (2011). Problematic Video Game Use: Estimated Prevalence and Associations with Mental and Physical Health. Cyberpsychology, behaviour, and social networking, 14 (10): 591 596.

Olson, C. K., Kutner, L. A. \& Warner, D. E. (2008). The role of violent video game content in adolescent development: Boys' perspectives. Journal of adolescent research, 23 (1): $55-75$.

Puri, k. \& Pugliese, R. (2012). Sex, lies, and video games: Moral 
panics of uses and gratifications. Bulletin of science, technology \& Society, 32 (5): $345-352$.

Rehbein, F., Kleimann, M., Moble, T. (2010). Prevalence and Risk Factors of Video Game Dependency in Adolescence: Results of a German Nationwide Survey. Cyberpsychology, behaviour and social networking, 13 (3): 269 - 277.

Quaresh, H. S., Khan, M. J. \& Masroor, U. (2013). Increased Aggression and Loneliness as Potential Effects of Pathological Video-Gaming among Adolescents. Pakistan Journal of Social and Clinical Psychology, 11 (1): 66 - 71

Schmitt, Z. L. \& Livingston, M. G. (2015). Video Game Addiction and College Performance Among Males: Results from a 1 Year Longitudinal Study. Cyberpsychology, Behavior, and Social Networking, 18(1): 25-29.
Weis, R. \& Cerankosky, B. C. (2010). Effects of video-game ownership on young boys' academic and behavioral functioning: a randomized, controlled study. Psychological sciences, 21 (4): $463-470$.

Wittek, C. T., Finseras, T. R., Pallesen, S., Mentzoni, R. A., Hanss, D., Griffiths, M. D. \& Molde, H. (2015). Prevalence and Predictors of Video Game Addiction: A Study Based on a National Representative Sample of Gamers. International journal of mental health and addiction. Retrieved from: http://link.springer.com/article/10 .1007/s11469-015-95928/fulltext.html

Wood, R. T. A., Griffiths, M. D. \& Parke, A. (2007). Experiences of Time Loss among Videogame Players: An Empirical Study. Cyberpsychology and behaviour, 10 (1): $38-44$. 